\title{
A new species of Corynespora causing foliar disease on Ficus religiosa from forest of Sonebhadra, Uttar Pradesh, India
}

\section{Singh $\mathbf{A}^{\mathbf{1}}$, Kumar $\mathbf{S}^{\mathbf{2}^{*}}$, Singh $\mathbf{R}^{3}$ and Dubey $\mathrm{NK}^{\mathbf{1}}$}

${ }^{1}$ Center of Advanced Study in Botany, Banaras Hindu University, Varanasi 221005 (U.P.), India

${ }^{2}$ Herbarium Division, Birbal Sahni Institute of Palaeobotany, 53, University Road, Lucknow-226007(U.P.), India.

${ }^{3}$ Department of Botany, D.D.U. Gorakhpur University, Gorakhpur-273009 (U.P.), India.

Singh A, Kumar S, Singh R, Dubey NK 2012 - A new species of Corynespora causing foliar disease on Ficus religiosa from forest of Sonebhadra, Uttar Pradesh, India. Mycosphere 3(5), 890892, Doi 10.5943 /mycosphere/3/6/2

A new species of Corynespora is described, illustrated and compared to similar species. $C$. ficigena sp. nov. was collected on Ficus religiosa (Moraceae) from forest flora of Sonebhadra, Uttar Pradesh, India.

Key words - Corynespora - Foliicolous hyphomycete - Fungi - Morphotaxonomy - New species

\section{Article Information}

Received 17 October 2012

Accepted 23 October 2012

Published online 5 November 2012

*Corresponding author: Shambhu Kumar - e-mail - skumartaxon@ gmail.com

\section{Introduction}

During our recent survey (2007-2009) of the forest region of Sonebhadra of District Mirzapur, Uttar Pradesh, a large number of collections showing foliar disease have been encountered. Within these, a new species, Corynespora ficigena on Ficus religiosa (Moraceae) was found. A description and illustration of the taxon is presented in this paper.

\section{Methods}

Surface scrapping and free hand cut sections of infected leaf samples, collected from Sonebhadra forests of Uttar Pradesh, were taken through infection spots and mounted in lactophenol cotton-blue mixture for microscopic examination, camera lucida drawing and micrometry. Type specimens have been deposited in Herbarium Cryptogamiae Indiae Orientalis (HCIO), Indian Agriculture Research Institute (IARI), New Delhi and their isotopes have been retained in the departmental herbarium for further reference. Morphotaxonomic comparisons were made with allied taxa and by consulting the current literature pertaining to taxonomy of Corynespora. Descriptions and nomenclatural details were deposited in MycoBank (www.Mycobank.org).

\section{Results}

\section{Taxonomy}

Corynespora ficigena Archana Singh, Sham. Kumar, R. Singh \& Dubey sp. nov. Fig. 1 MycoBank MB 801329

Leaf spot amphigenous, subcircular to irregular, spreading on entire leaf surface, necrotic, brown to dark brown, up to $10 \mathrm{~mm}$ in diam. Colonies hypophyllous, effuse. Mycelium internal, composed of branched, septate, thin-walled, smooth, subhyaline to olivaceous hyphae. Stromata absent. Conidiophores macronematous, mononema- 


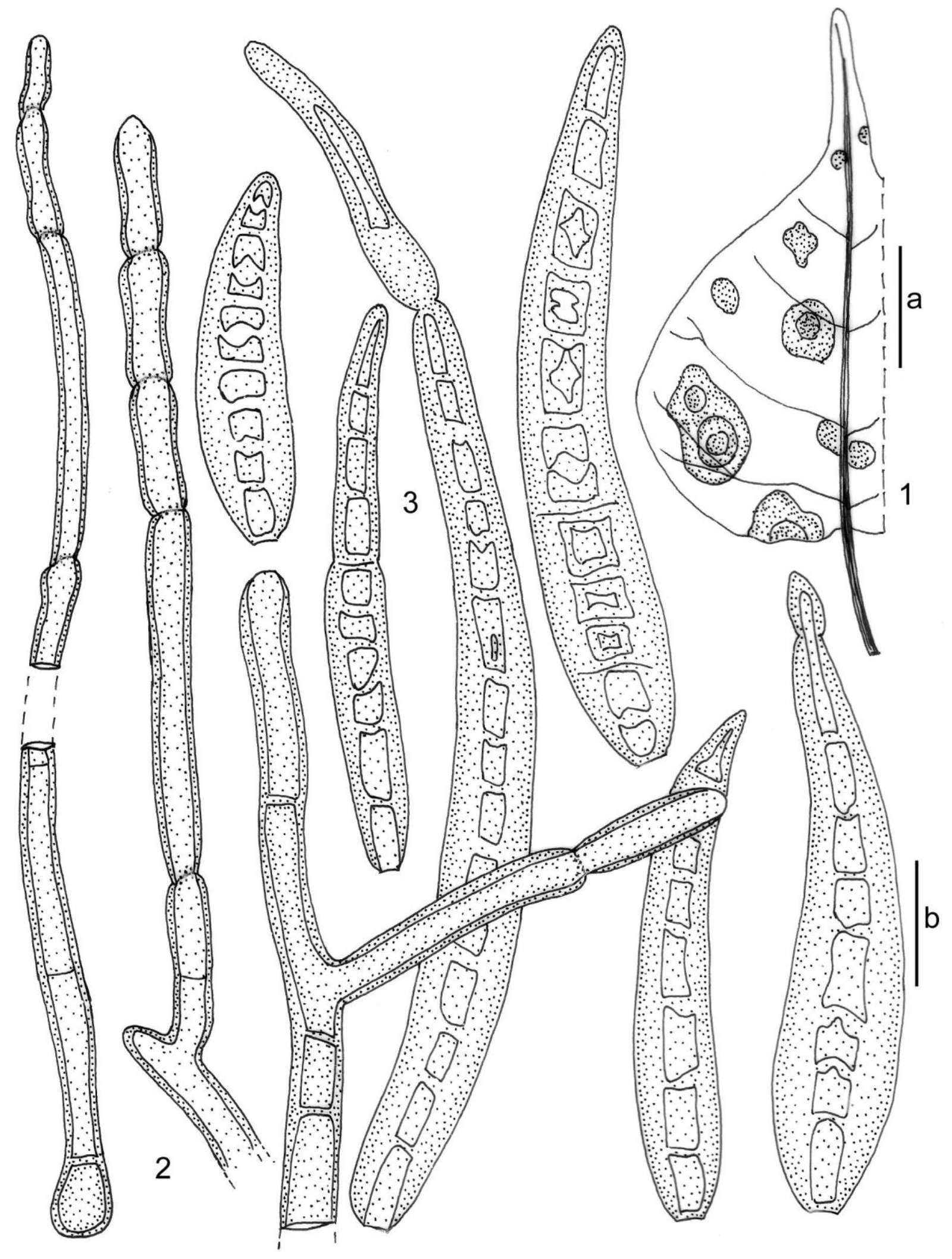

Fig. 1 - Corynespora ficigena. 1 Infection spots 2 Conidiophores. 3 Conidia. Bars $a=20 \mathrm{~mm}, \mathrm{~b}=$ $20 \mu \mathrm{m}$. 
tous, arising singly from hyphae, erect, straight to flexuous, smooth, thick- walled, cylindrical, branched, pale brown to brown, up to 10septate, 2-4 successive, cylindrical, terminal proliferations, dark brown $135-400 \times 6-8 \mu \mathrm{m}$. Conidiogenous cells integrated, terminal or intercalary, monotretic, smooth, cylindrical, scars unthickened, swollen towards apex. Conidia acrogenous, solitary, simple, dry, thinwalled, smooth, straight to slightly curved, obclavato-cylindrical, 7-13- distoseptate, apex obtuse, base obclavate, light olivaceous brown, hilum unthickened, germinating conidia with germ tube are observed, 90-165 ×9-20 $\mu \mathrm{m}$.

Type - On living leaves of Ficus religiosa L. (Moraceae), Sonebhadra, (U.P.), India, Nov. 2009, coll. Archana Singh BHU Herb No. 9098 (isotype), HCIO 50142 (holotype). the host genus.

Etymology - ficigena in reference to

Perusal of literature revealed that two species of Corynespora viz. C. fici-altissimae X.G. Zhang \& J.J. Xu (Zhang \& Xu 2005) and C. fici-benjaminae H.B. Fu \& X.G. Zhang \& Zhang (Zhang et al. 2009) have been described on the host genus. Hence, the morphology of the new species was compared with these two taxa.

From comparison, it is clear that the conidiophores are unbranched in $\mathrm{C}$. ficialtissimae and $C$. fici-benjaminae while branched in $C$. ficigena. The conidiophores of C. ficigena are smaller $(135-400 \times 6-8 \mu \mathrm{m})$ with fewer proliferations $(2-3)$ than in $C$. ficialtissimae $(30-65 \times 5-6 \mu \mathrm{m})$ and $C$. ficibenjaminae $(152-467 \times 5.5-11 \mu \mathrm{m})$. The conidia are longer $(90-165 \times 9-20 \mu \mathrm{m})$ in $C$. ficigena than $C$. fici-altissimae $(55-85 \times 9-12$ $\mu \mathrm{m})$ and $C$. fici-benjaminae $(51.5-71 \times 8-11$ $\mu \mathrm{m})$. The conidia of $C$. ficigena have 7-13 distosepta while $C$. fici-altissimae has 11-18 and $C$. fici-benjaminae has 5-10.

Therefore, the present species merits recognition as a new taxon.

\section{Acknowledgements}

Authors are grateful to the Head, Department of Botany, Banaras Hindu University (BHU), Varanasi, Uttar Pradesh, India for providing library and laboratory facilities. Author's thanks are also due to the Curator, Herbarium Cryptogamiae Indae Orientalis (HCIO), Indian Agriculture Research Institute (IARI), New Delhi for depositing the holotype specimens and providing accession numbers thereof. Dr. Archana Singh is thankful to Department of Science and Technology, Government of India, New Delhi for providing financial support under Women Scientist Scheme (WOS-A). Authors are also thankful to Anonymous for critical review of the manuscript.

\section{References}

Zhang Xiu-Guo, Xu Jun-Jie. 2005 Taxonomic studies of Corynespora from Guangxi, China. Mycotaxon 92, 431-436.

Zhang K, Fu Hong-Bo, Zhang Xiu-Guo. 2009

- Taxonomic studies of Corynespora from Hainan, China. Mycotaxon 109, 85-93. 